\title{
The novel use of "point of care" devices to evaluate transport duration on selected pork quality parameters
}

\author{
M.L. Seshoka ${ }^{1,2}$, A.T. Kanengoni ${ }^{1 \#}$, F.K. Siebrits ${ }^{2}$ \& K.H. Erlwanger ${ }^{3}$ \\ ${ }^{1}$ ARC-Animal Production Institute, Private Bag X2, Irene, 0062, South Africa \\ ${ }^{2}$ Department of Animal Science Tshwane University of Technology, Private Bag X 640 Pretoria 0001 \\ ${ }^{3}$ School of Physiology, Faculty of Health Sciences, University of the Witwatersrand, Private Bag X 3, \\ Wits 2050 South Africa
}

(Received 30 September 2012; Accepted 12 March 2013; First published online 5 July 2013)

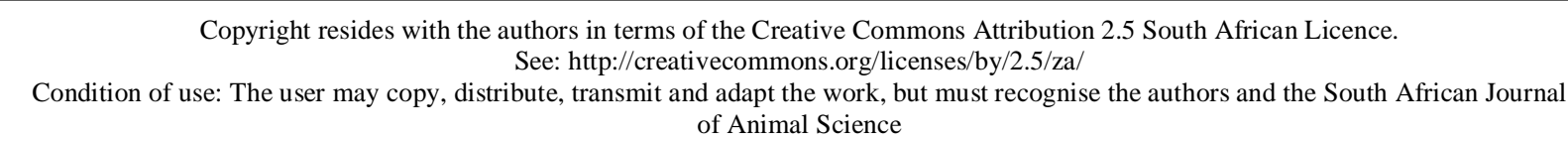

\begin{abstract}
Point-of-care (POC) devices were used to measure plasma metabolic substrates in pigs subjected to stressful conditions. These were then related to the meat $\mathrm{pH}$, drip loss and carcass temperature. Forty Large White x Landrace pigs (20 females and 20 males) weighing approximately $67 \pm 6.5$ kg were used in the study. Twenty of the pigs were subjected to a stressful regimen for two hours and the other 20 pigs were transported for 15 minutes from their pens directly to the abattoir. Salivary cortisol, plasma glucose, triglycerides and lactate concentrations were determined before and after transportation to the abattoir and carcass temperature, $\mathrm{pH}$ and drip loss were measured after slaughter. There were no differences in the lactate, cortisol, $\mathrm{pH}$ and triglycerides measurements from the pigs of different sexes. Female pigs had higher carcass temperature and lower glucose levels than male pigs. Regression analysis showed that back fat and lactate accounted for $99 \%$ of variation in the $\mathrm{pH}_{24 \mathrm{~h}}$ of pigs transported over a short duration while lactate was responsible for only $16 \%$ of the variation in pigs transported over the long duration. The difference in lactate accounted for $78 \%$ of variation in the carcass temperature at 45 minutes for pigs transported over the short duration while in the long duration group, the weight was responsible for $81 \%$ of the variation. In conclusion, POC devices measured differences in lactate concentrations in pigs transported over different durations and relationships between the lactate and the carcass $\mathrm{pH}$, carcass temperature and drip loss was determined.
\end{abstract}

Keywords: Stress, long and short duration, animal welfare

\# Corresponding author: Arnoldk@arc.agric.za

\section{Introduction}

Poor pork quality as a result of pre-slaughter stress is widespread in the industry and this is of great concern (Hambrecht et al., 2004; Hoffman \& Fisher, 2010). It occurs to such an extent that even stress resistant breeds are affected (Hambrecht et al., 2004; Küchenmeister et al., 2005). Therefore, careful handling of the pigs and good handling practises are essential at all stages of production, right up to slaughter in order to produce good quality pork (Keith et al., 2002). Since the psychological and physical stressors associated with transportation in pigs lead to adaptive responses that can be measured behaviourally and physiologically (Nanni-Costa, 2009), this provides a mechanism of quantifying the levels of stress and managing it.

Many existing methods used for assessing stress levels and consequently welfare tend to be invasive (viz. blood sampling), impractical (viz. collars for measuring heart rate) or time-consuming (viz. behavioural analysis) (Lane et al., 2002). Given that abattoirs slaughter many pigs daily, there is a need for quick, reliable 
methods for assessing stress and at the same time allowing good decisions to be made at a relatively low cost. In medical circles, "point-of-care" (POC) diagnostic testing, performed at the patient's bedside or in a doctor's surgery, allowing physicians to diagnose patients more rapidly than traditional laboratory-based testing, is well established (Lane et al., 2002; Luley et al., 2000). Based on this concept, a rapid diagnostic kit for the assessment of pig salivary cortisol levels was developed using lateral flow technology, one of the main principles used in the POC tests involving the immuno-chromatographic or lateral flow devices (LFDs) exemplified in the home pregnancy test (Lane et al., 2002). However, other potentially viable rapid diagnostic tests already being used to routinely monitor blood glucose, lactate and triglycerides in the medical fraternity have not been used to assess stress in pigs.

The objective of the study was therefore, to measure the levels of metabolic substrates in pig saliva and plasma subjected to stressful conditions using rapid diagnostic tests and relate them to the $\mathrm{pH}$, drip loss and carcass temperature of the meat. It was envisaged that such a relationship if established would enable the identification of stressed pigs likely to produce poor quality pork and enable prophylactic measures to be taken before slaughter to come up with good quality pork.

\section{Materials and Methods}

The study was conducted at the Pig Production unit of the Agricultural Research Council Animal Production Institute (ARC-API) in Irene, South Africa (longitude $28^{\circ} 13^{\prime}$ S: latitude 25 55' E, altitude 1524 $\mathrm{m})$ about 15 kilometres South of Pretoria and was approved by the Animal Ethics Committee at Irene (Ethics number: APIEC08/10). Forty Large White x Landrace pigs (20 males and 20 females) weighing approximately $67 \pm 6.5 \mathrm{~kg}$ at the age of 5 - 6 months were randomly selected from the pig herd at ARC-API. The 40 pigs were selected from 10 pens holding 12 pigs each by randomly selecting four pigs from each pen. The pigs were housed in $5 \times 3 \mathrm{~m}$ fully slatted pens with concrete floors, in enclosed and temperaturecontrolled houses. The pigs were fed a commercial grower diet (14 MJ DE/kg, 16 g CP/kg, 0.82\% lysine) ad libitum to meet and exceed the recommended nutrient requirements for growing pigs (NRC, 1998) while water was freely available throughout the study. A 2 x 2 factorial design (duration x sex) with the treatments identified as follows; males transported over long (ML) and short (MS) duration and females transported over long (FL) and short (FS) duration was used for this study. Just before slaughter, 10 male and 10 female pigs were subjected to a stressful transport regimen consisting of transporting the pigs along the bumpy back roads around the ARC-API premises for two hours in a pickup truck. The remaining 10 male and 10 female pigs were transported for 15 minutes from the pens directly to the abattoir in the same pickup truck.

Saliva samples were collected from each pig; the day before slaughter to get baseline measurements, on the day of slaughter before transportation to the abattoir and again after transportation just before slaughter. This was done by allowing individual pigs to chew cotton balls attached to pieces of string for 1 - 2 minutes until the buds were thoroughly moistened. The saliva was transferred to test tubes using syringes and then stored in separate vials at $-20{ }^{\circ} \mathrm{C}$ until analysis for cortisol. Plasma glucose, triglycerides and lactate concentrations were determined by pricking the ear vein of each pig and transferring the drops of blood into test strips which were then inserted in POC devices (Accutrend ${ }^{\circledR}$ Plus, Roche Diagnostics GmbH, Germany; Glucometer Elite, Bayer) for immediate readings.

The pigs were slaughtered humanely by electrical stunning and exsanguination based on procedures approved by the ARC-API Animal Ethics Committee. The warm carcass weight was measured after dressing using an overhead scale. At 45 minutes and 24 hours after slaughter, $\mathrm{pH}$ and temperature readings were taken from the longissimus thoracis muscle with a portable $\mathrm{pH}$ metre between the $3^{\text {rd }}$ and the $4^{\text {th }}$ rib (EUTECH Instruments, Thermo Fisher Scientific). The pH meter and electrode were first calibrated at $\mathrm{pH} 4$ and $\mathrm{pH} 7$ before use and then re-calibrated in $\mathrm{pH}$ buffers after every $4^{\text {th }}$ reading. The carcasses were then placed in a cold room, kept at an approximate temperature of $0{ }^{\circ} \mathrm{C}$ for 24 hours and then the resulting cold carcass weights were then measured. The carcasses were then split into two parts along the median plane from the remaining sacral vertebra to the first cervical vertebra with a carcass splitting bandsaw and back fat was measured between the $2^{\text {nd }}$ and $3^{\text {rd }}$ last rib about $60 \mathrm{~mm}$ from the mid line on the left side of the carcass using a pair of Vernier calipers. Carcass drip loss was then calculated from the difference between warm and cold carcass weights divided by the warm carcass weight. Cortisol concentration was measured using a commercial ELISA kit ${ }^{\circledR}$ (SKGE008, R\&D Systems, Inc. Minneapolis, MN, USA). The absorbance of samples and standards was determined using a micro plate reader (Multiskan Ascent ${ }^{\circledR}$, Helsinki, Finland) and a standard curve was generated from the measurements. Salivary cortisol concentrations were then calculated 
based on the standard curve. All data were tested for constant variance and departures from normal distribution using the Kolmogorov-Smirnov Test in SAS (SAS, 2004). Least square means of blood glucose, lactate, triglycerides, cortisol, $\mathrm{pH}$ of sex and transport duration were generated using the LSMeans Statement and analysed using ANOVA of SAS (SAS, 2004). The model used was:

$$
Y_{i j k}=\mu+G_{i j}+T_{i j}+D_{i j}+(G * T)_{i j k}+(G * D)_{i j}+(T * D)_{i j}+e_{i j k}
$$

where $\mathrm{Y}=$ blood glucose, lactate, triglyceride, cortisol and $\mathrm{pH} ; \mathrm{G}=$ gender (male vs. female); $\mathrm{T}=$ time 1 and $2 ; \mathrm{D}=$ duration (short vs. long duration); $\mathrm{G}^{*} \mathrm{~T}$ (gender $\mathrm{x}$ time); $\mathrm{G}^{*} \mathrm{D}=$ gender $\mathrm{x}$ duration; $\mathrm{T} * \mathrm{D}=$ time $\mathrm{x}$ duration and $\mathrm{e}=$ error.

Pairwise comparisons between sex and transport duration means were made using pdiff (SAS, 2004) and differences were considered significant if $P<0.05$. Correlation coefficients were calculated using PROC CORR (SAS, 2004) to examine the relationships between metabolic and carcass traits and the meat quality traits. Relationships between parameters were considered significant if $P<0.05$. Stepwise linear regression using the forward selection method SAS (2004) was used to predict the meat quality traits based on the metabolic substrates and the live weight, warm and cold carcass weights, back fat thickness and dressing percentage.

\section{Results and Discussion}

The least square means of the metabolic substrates and meat quality of grower pigs transported over short and long duration are shown in Table 1. Transportation affected the levels of glucose, lactate and salivary cortisol $(P<0.05)$ but had no effect $(P>0.05)$ on triglyceride levels regardless of duration. The lactate levels from females and males which were transported over a short duration were high and similar $(P$ $>0.05)$ but were significantly different over the longer duration $(P<0.05)$, with the females having lower levels $(P>0.05)$. Lactate production occurs when the body switches from the aerobic to anaerobic respiration (Allison et al., 2006). This will most often occur after strenuous exercise as pigs are loaded into the truck and also when they fight. The results suggest that the males maintained high lactate levels through stressful activities over the long duration whereas the females rested and recovered. Plasma lactate is an indicator of both physical and psychological stress associated with handling of pigs immediately before slaughter (Hambrecht et al., 2004), therefore the levels suggest that there was more stress in female pigs in the short duration trip than the long duration one. The females had a higher $(P<0.05) \mathrm{pH}_{24 \mathrm{~h}}$ than the males for transportation periods which lasted for a short interval, but there were no sex differences $(P>0.05)$ over the long duration. Changes in $\mathrm{pH}$ and temperature post mortem are influenced by pre-slaughter muscle

Table 1 The least square means of the metabolic substrates and meat quality of grower pigs transported over short or long duration

\begin{tabular}{|c|c|c|c|c|c|c|c|c|c|}
\hline \multirow{2}{*}{ Parameters $^{\mathrm{a}}$} & \multicolumn{2}{|c|}{ Short duration } & \multicolumn{2}{|c|}{ Long duration } & \multirow{2}{*}{ SEM } & \multicolumn{4}{|c|}{ Probability $^{b}$} \\
\hline & $\mathbf{F}$ & $\mathbf{M}$ & $\mathbf{F}$ & $\mathbf{M}$ & & Transport & Gender & Duration & $\begin{array}{l}\text { Gender } x \\
\text { duration }\end{array}$ \\
\hline Lactate $(\mathrm{mmol} / \mathrm{L})$ & 8.8 & 7.3 & 2.9 & 7.4 & 0.64 & $* * *$ & NS & $* * *$ & ** \\
\hline Glucose(mmol/L) & 4.5 & 4.9 & 4.0 & 4.6 & 0.12 & $* * *$ & NS & NS & NS \\
\hline Cortisol (mmol/L) & 5.6 & 3.5 & 5.0 & 4.0 & 0.63 & $* * *$ & NS & NS & NS \\
\hline $\mathrm{C}_{\mathrm{T}}\left({ }^{\circ} \mathrm{C}\right)$ & 19.0 & 18.4 & 19.1 & 18.6 & 0.21 & $* * *$ & $*$ & NS & NS \\
\hline $\mathrm{pH}_{24 \mathrm{~h}}$ & 5.40 & 5.28 & 5.32 & 5.26 & 0.05 & $* * *$ & NS & NS & NS \\
\hline $\begin{array}{l}\text { Triglycerides } \\
(\mathrm{mmol} / \mathrm{L})\end{array}$ & 0.8 & 0.7 & 0.8 & 0.8 & 0.05 & NS & NS & NS & NS \\
\hline
\end{tabular}

F: female; M: male;

${ }^{\mathrm{a}} \mathrm{C}_{\mathrm{T}}\left({ }^{\circ} \mathrm{C}\right)$ : carcass temperature; $\mathrm{pH}_{24 \mathrm{hr}}$ : $\mathrm{pH}$ at 24 hours;

${ }^{\mathrm{b}} \mathrm{NS}$ : not significant; $P>0.05$; $* P<0.05 ; * * P<0.01$; $* * * P<0.001$. 
activity or elevated pre-slaughter muscle temperature (Klont \& Lambooij, 1995). A possible explanation for the $\mathrm{pH}$ results in this study is that pigs transported over the short duration did not get enough time to recover from the exertions of loading unlike those transported over the longer duration.

The correlation coefficients of the metabolic substrates with carcass temperature $\left(\mathrm{C}_{\mathrm{T} 45 \min }\right.$ and $\left.\mathrm{C}_{\mathrm{T} 24 \mathrm{~h}}\right)$, carcass $\mathrm{pH}\left(\mathrm{pH}_{24 \mathrm{~h}}\right.$ and $\left.\mathrm{pH}_{45 \min }\right)$ and with carcass drip loss (CDL) in grower pigs transported over short (SD) and long (LD) duration are shown in Table 2. There was a negative correlation between lactate and $\mathrm{C}_{\mathrm{T} 45 \mathrm{~min}}$ and $\mathrm{C}_{\mathrm{T} 24 \mathrm{~h}}(P<0.05)$ for the long duration pigs which is similar to the results obtained by Hambrecht $e t a l$. (2004). Lactate was also correlated to $\mathrm{pH}_{24 \mathrm{~h}}$ and $\mathrm{CDL}(P<0.05)$ for the pigs transported over the short duration. The other correlations were between cortisol and TG with $\mathrm{pH}_{24 \mathrm{~h}}(P<0.05)$. There were no correlations between the metabolic substrates lactate, glucose, cortisol, triglycerides and $\mathrm{pH}_{45 \min }$ for all the treatments after transportation. Meat quality traits are affected by numerous and complex factors, often resulting in no clear relationships with single parameters; for example drip loss in pork is influenced by rate of $\mathrm{pH}$ decline, ultimate $\mathrm{pH}$, the presence of the halothane gene and transportation among others (Perez et al., 2002; Rosenvold \& Andersen, 2003; Zhang et al., 2006; Fischer, 2007).

Table 2 Correlation coefficients of the metabolic substrates with Carcass Temperature $\left(\mathrm{C}_{\mathrm{T} 45 \mathrm{~min}}\right.$ and $\left.\mathrm{C}_{\mathrm{T} 24 \mathrm{~h}}\right)$, carcass $\mathrm{pH}\left(\mathrm{pH}_{24 \mathrm{~h}}\right.$ and $\left.\mathrm{pH}_{45 \mathrm{~min}}\right)$ and with carcass (CDL) drip loss in grower pigs transported over short (SD) and long (LD) duration

\begin{tabular}{lccccc}
\hline Parameters & Trt & Lact & Glu & Cort & TG \\
\hline \multirow{3}{*}{$\mathrm{C}_{\text {T45min }}$} & SD & 0.02 & -0.18 & 0.77 & 0.05 \\
& LD & $-0.47^{*}$ & -0.19 & 0.26 & -0.06 \\
\cline { 2 - 6 } $\mathrm{C}_{\text {T24h }}$ & SD & 0.29 & -0.37 & 0.53 & 0.31 \\
& LD & $-0.77^{* * *}$ & -0.42 & 0.27 & -0.02 \\
\cline { 2 - 6 } $\mathrm{pH}_{45 \min }$ & $\mathrm{SD}$ & -0.22 & -0.01 & -0.57 & -0.12 \\
& $\mathrm{LD}$ & -0.23 & 0.02 & 0.02 & -0.01 \\
$\mathrm{pH}_{24 \mathrm{~h}}$ & $\mathrm{SD}$ & $0.70^{* * *}$ & 0.22 & $0.83^{*}$ & $-0.55^{*}$ \\
& $\mathrm{LD}$ & -0.32 & -0.21 & -0.24 & -0.19 \\
$\mathrm{n} \mathrm{CDL}$ & $\mathrm{SD}$ & $0.47^{*}$ & -0.26 & -0.27 & 0.35 \\
& $\mathrm{LD}$ & -0.24 & 0.09 & 0.004 & 0.02 \\
\hline
\end{tabular}

Lact: lactate; Glu: glucose; Cort: cortisol; TG: tryglycerides.

$\mathrm{C}_{\mathrm{T} 45 \min }$ : carcass temperature at 45 minutes; $\mathrm{C}_{\mathrm{T} 24 \mathrm{~h}}$ : carcass temperature at 24 hours; $\mathrm{pH}_{24 \mathrm{~h}}$ : $\mathrm{pH}$ at 24 hours; $\mathrm{pH}_{45 \min }$ : $\mathrm{pH}$ at 45 minutes.

SD: short duration; LD: long duration;

$* P<0.05 ; * * P<0.01$; *** $P<0.001$.

The single and multiple prediction equations for $\mathrm{pH}_{24 \mathrm{~h}}$, change in carcass temperature and loin drip loss in pigs transported over short and long duration are shown in Table 3. The extent to which the metabolic substrates explained the variation in the meat quality was deduced from the coefficient of determination $\left(\mathrm{R}^{2}\right)$ of the equations. The remaining percentage was taken as the unknown variables or inherent variability. Regression analysis showed that back fat and lactate accounted for approximately $99 \%$ of the variation in the $\mathrm{pH}_{24 \mathrm{~h}}$ of pigs transported over short duration while lactate could account for only about $16 \%$ of the variation in pigs transported over the long duration. This implies that while $\mathrm{pH}$ and backfat can be used to predict $\mathrm{pH}_{24 \mathrm{~h}}$ fairly accurately in pigs after travelling a short duration there are other parameters not measured in this study that could affect the ultimate $\mathrm{pH}$ of the pigs after long duration. However, since pre-slaughter stress results in high lactate levels which have been linked to poor meat quality in a number of studies (Hambrecht et al., 2004; 2005; Edwards et al., 2010; Muta-Rojas et al., 2012), there is a need to establish a more robust relationship to enable the use of lactate to make better predictions of meat quality. 
The difference in lactate levels before and after transportation accounted for $78 \%$ of the variation in the carcass temperature at 45 minutes for pigs transported over short duration. It is critical to estimate these parameters because post mortem $\mathrm{pH}$ and temperature influence the rate and extent of protein denaturation, oxidation, proteolysis and lipid oxidation (Rosenvold \& Anderson, 2003). Hambrecht et al. (2004) noted that high pre-slaughter stress in pigs increases the carcass temperature and decreases $\mathrm{pH}$ at 30 minutes post mortem.

Table 3 Single and multiple prediction equations for $\mathrm{pH}_{24 \mathrm{~h}}$, carcass temperature $\left({ }^{\circ} \mathrm{C}\right)$ and drip loss in pigs transported over short and long duration

\begin{tabular}{|c|c|c|c|c|c|c|}
\hline \multirow{2}{*}{$\begin{array}{l}\text { Parameter }^{\mathrm{a}} \\
\text { Treatment }^{\mathrm{b}}\end{array}$} & \multicolumn{2}{|c|}{$\mathbf{p H}_{24 h}$} & \multicolumn{2}{|c|}{$\mathrm{CT}_{45 \min }\left({ }^{\circ} \mathrm{C}\right)$} & \multicolumn{2}{|c|}{ Drip loss (\%) } \\
\hline & SD & LD & SD & LD & SD & LD \\
\hline $\mathrm{R}^{2}$ & 0.99 & 0.16 & 0.78 & 0.81 & 0.20 & 0.57 \\
\hline Intercept $^{\mathrm{c}}$ & 4.77 & 5.23 & 4.00 & 37.85 & -2.10 & -31.44 \\
\hline \multicolumn{7}{|l|}{ Variables $^{\mathrm{d}}$} \\
\hline Back fat & 0.05 & & & & & \\
\hline Lactate & 0.02 & 0.03 & & & & \\
\hline Dressing\% & & & & & & 0.43 \\
\hline Weight & & & & 0.09 & 0.06 & \\
\hline Lactate difference & & & -0.40 & & & \\
\hline
\end{tabular}

\section{Conclusion}

Transportation, both long and short duration, affected the levels of lactate, glucose and salivary cortisol levels and the differences were measured by the POC tests. There were differences on the impact of transport duration on lactate levels and also on the carcass temperature, drip loss and $\mathrm{pH}$. There were relationships between the metabolic substrates and meat quality traits measured in the study. More studies need to be carried out to develop more precise prediction equations under different production and transportation conditions. Point of care devices can be used to determine the glucose and lactate changes in pigs before slaughter hence they have a potential role in mitigating against poor pork quality due to preslaughter stress.

\section{Acknowledgements}

The authors are grateful to the Professional Development Programme (PDP) of the ARC-API at Irene for financial support through the course of the study, the South African Pork Producer's Organization for additional funds for the project, M. Badenhorst, and the University of Witwatersrand for the use their laboratory and facilities for analysis.

\section{References}

Allison, C.P., Marr, A.L., Berry, N.L., Anderson, D.B., Ivers, D.J., Richardson, L.F., Johnson, R.C. \& Doumit, M.E., 2006. Effects of halothane sensitivity on mobility status and blood metabolites of hal-1843-normal pigs after rigorous handling. J. Anim. Sci. 84, 1015-1021.

Edwards, L.N., Engle, T.E., Correa, J.A., Paradis, M.A., Grandin, T. \& Anderson, D.B., 2010. The relationship between exsanguination blood lactate concentration and carcass quality in slaughter pigs. Meat Sci. 85, 435-44. 
Fischer, K., 2007. Drip loss in pork: influencing factors and relation to further meat quality traits. J. Anim. Breed. Genet. 124, 12-18.

Hambrecht, E., Eissen, R.I.J., Ducro, B.J., Smiths, C.H., Den Hartog, L.A. \& Verstegen, M.W., 2004. Preslaughter stress and muscle energy largely determine pork quality at two commercial processing plants. J. Anim. Sci. 82, 1401-1409.

Hambrecht, E., Eissen, J.J., Newman, D.J., Smits, C.H.M., Den Hartog, L.A. \& Verstegen, M.W.A., 2005. Negative effects of stress immediately before slaughter are aggravated by suboptimal transport and lairage conditions. J. Anim. Sci. 83, 440-448.

Hoffman, L.C. \& Fisher, P., 2010. Comparison of the effects of different transport conditions and lairage times in a Mediterranean climate in South Africa on the meat quality of commercially crossbred Large white x Landrace pigs. J. S. Afr. Vet. Assoc. 81, 225-227.

Keith, E.B., John, A.S., Gary, C. \& Grandin, T., 2002. The relationship between good handling / stunning and meat quality in beef, pork and lamb. Meat Sci. 61, 21-22.

Klont, R.E. \& Lambooji, E., 1995. Influence of preslaughter muscle temperature on muscle metabolism and meat quality in anesthetized pigs of different halothane genotypes. J. Anim. Sci. 73, 96-107.

Küchenmeister, U. Kuhn, G. \& Ender, K., 2005. Pre-slaughter handling of pigs and the effect on heart rate, meat quality, including tenders and sarcoplasmic reticulum $\mathrm{Ca}^{2+}$ transport. Meat Sci. 71, 690-695.

Lane, J., Flint, J. \& Danks, C., 2002. The development of a rapid diagnostic test for cortisol in the saliva of pigs. Int. J. Appl. Res. Vet. Med. 7, 4.

Luley, G.R., Reuter, W., Paal, V. \& Detlev Gottschling, H., 2000. Physiological responses of growing pigs exposed to a diurnal pattern of heat stress. Westphal; Clin. Chem. p. 46.

Muta-Rojas, D., Becerril-Herrera, M., Roldan-Santiago, P., Flores-Peinado, S. \& Mora-medina, P., 2012. Effects of long duration transportation and $\mathrm{CO}_{2}$ stunning on critical blood values in pigs. Meat Sci. 90, 893-898.

Nanni-Costa, L., 2009. Short-term stress: The case of transport and slaughter. J. Anim. Sci. 8, 241-252.

NRC, 1998. Nutrition Requirement of Swine. National Academy Press, Washington, D.C., USA.

Pérez, M.P., Palacio, J., Santolaria, M.P., Chacon, G., Calvo, J.H. \& Beltran, J.A., 2002. Effect of transport time on welfare and meat quality in pigs. Meat Sci. 61, 425-433.

Rosenvold, K. \& Anderson, H., 2003. Factors of significance for pork quality - A Review. Meat Sci. 64, 219-237.

SAS, 2004. SAS user's guide: statistics. SAS Inst, Inc., Cary, N.C., USA.

Zhang, W.G., Lonergan, S.M., Gardener, M.A. \& Huff-Lonergan, E., 2006. Contribution of post-mortem changes of integrin, desmin and $\mu$-calpain to variation in water holding capacity of pork. Meat Sci. 74, 578-585. 